\title{
ANTONIO GRAMSCI Y LAS RAÍCES LEJANAS DEL EUROCOMUNISMO: EL PRECEDENTE OLVIDADO
}

\begin{abstract}
David Caldevilla Domínguez: Universidad Complutense de Madrid. España. Enrique García García: Universidad San Pablo CEU. España.
\end{abstract}

\section{RESUMEN}

El concepto Gramsciano de hegemonía plantea un escenario hipotético para la lucha de clases o enfrentamiento social, muy distinto al plano revolucionario ordinario: el escenario cultural. El viejo concepto militar de ganar las mentes y los corazones de la gente para lograr la victoria, se aplica en este caso a los fines de la revolución. Y pese a haberse formulado en los años 20, tardo cincuenta años en convertirse en una idea predominante en los principales partidos europeos.

\section{PALABRAS CLAVE}

Hegemonía - Gramsci - Marxismo - Cultura - Eurocomunismo - PCI - Socialismo Neogramscianismo - Socialismo científico

\section{ANTONIO GRAMSCI AND THE FAR ROOTS OF EURO-COMMUNISM: THE FORGOTTEN PRECEDENT}

\begin{abstract}
Gramsci's Hegemony concept focuses an unusual scenario for class-fighting, different to the usual revolutionary focus: cultural scenario. The old military concept of conquering the people's Hearts and Minds to achieve Victory applies here, to the Revolution's ends. And being formulated in the 20's, it took 50 years to reach the main European parties.
\end{abstract}

\section{KEY WORDS}

Hegemony - Gramsci - Marxism - Culture - Eurocomunism - PCI - Socialism Neogramscianism - Scientific socialism

\footnotetext{
${ }^{1}$ David Caldevilla Domínguez: Profesor de Relaciones Públicas en la Fac. de Ciencias de la Información de la Universidad Complutense. Autor de 7 libros y numerosos artículos científicos, es experto en comunicación persuasiva y en especial la política.
} 


\section{1.- INTRODUCCIÓN}

El presente contexto de crisis ha llevado al gran público a buscar soluciones en las alternativas y los modelos que ofrecen ideologías basadas en nuevos modos de organización social y a recuperar y revisar los antiguos (Dahrendorf, Touraine y, naturalmente, los neo-marxismos entre otros). Por primera vez en décadas, Escritos filosóficos y económicos (1844)2, El manifiesto [del partido] comunista (1848)3 -con 20.000 ejemplares vendidos en ocho ediciones desde 2002 al 2008- y El capital (1867-1894)4, obra póstuma de Karl Marx, volvieron a ser reeditados por el auge de la demanda en Occidente según el diario Público5, mientras el hombre de a pie del mundo privilegiado trataba de comprender por qué había dejado de serlo.

El marxismo moderno (encabezado por pensadores como Erik Olin Wright, Gerald Cohen o John Elster, considerados como los padres del 'Marxismo analítico' -corriente revisitadora del marxismo clásico desde la filosofía y la economía-) ha evolucionado, por imperativo de necesidad, tras el trauma que supuso, para su ideología, la caída del sistema soviético (1991). A fin de adecuarse a la nueva realidad en la que se desenvuelve, y en la que debe intentar medrar, ha matizado su discurso adaptándolo desde la abierta aceptación de la vía democrática, hasta convivir con el capitalismo, en simbiosis socialdemócrata. Para la consecución de este objetivo ha sido de crucial importancia rescatar el pensamiento de Antonio Gramsci (1891-1937) fundador del partido Comunista Italiano, cuyo concepto de 'Hegemonía' -la idea de que el control social es ejercido a través del predominio cultural y no de la fuerza o la coacción militar o policial- ha tenido una aparente repercusión en la mayoría de los llamados movimientos Neo-Marxistas que le han seguido. La violencia, tras las dos grandes guerras, no es aceptada de manera general y las adoctrinadas masas tampoco han sido educadas para exigir sino para rogar; idea con la que Gramsci estaría hoy muy de acuerdo, como se verá.

Si bien este concepto se puede tildar de cruce de caminos entre la superestructura de Marx y el concepto filosófico de 'principio rector' o 'hegemonikón' desarrollado en Meditaciones6 del emperador romano Marco Aurelio (121-180), llamado el filósofo, el aporte de Gramsci puede hallarse en el plano de la acción socialista primigenia para llegar a la fase comunista preconizada por Marx como evolución y resolución final de su lucha de clases como motor de la historia de la Humanidad.

Cuerpo, alma, inteligencia; propias del cuerpo, las sensaciones; del alma, los

\footnotetext{
2 Disponible en: http://pensaryhacer.files.wordpress.com/2008/06/manuscritos-filosoficos-y-economicos1844karl-marx.pdf

3 Disponible en: $w$ ww.educarteoax.com/pedagogizando/descargas/otros/Manifiesto_comunista.pdf 4 Disponible en: www.taringa.net/posts/info/10737381/Karl-Marx---El-Capital---Tomos-I-II-y-III.html 5 Informaciones publicadas el 26 de octubre de 2008 y disponible en: www.publico.es/dinero/168187/lavuelta-de-las-teorias-de-karl-marx, el 3 de noviembre del mismo año, disponible en: www.publico.es/culturas/170354/viva-marx-viva-el-el-capital. Hacen referencia a la situación en Alemania especialmente, donde el ministro de Finanzas, el socialdemócrata Peer Steinbrück, elogiaba a Marx como augur y vate de la actual crisis y guía para alguna posible solución. Y publicación del 17 de diciembre del 2008, disponible en: www.publico.es/culturas/183940/navidades-rojas, en la que hace referencia a las ventas e influencia en España.

6 Disponible en: www.edu.mec.gub.uy/biblioteca_digital/libros/M/Marco\%20Aurelio\%20\%20marco\%20aurelio\%20meditaciones.pdf
} 
instintos; de la inteligencia, los principios. Recibir impresiones por medio de la imagen es propio también de las bestias, ser movido como un títere por los instintos corresponde también a las fieras, a los andróginos, a Fálaris y a Nerón. Pero tener a la inteligencia como guía hacia los deberes aparentes pertenece también a los que no creen en los dioses, a los que abandonan su patria y a los que obran a su placer, una vez han cerrado las puertas. Por tanto, si lo restante es común a los seres mencionados, resta como peculiar del hombre excelente amar y abrazar lo que le sobreviene y se entrelaza con él. Y el no confundir ni perturbar jamás al Dios que tiene la morada dentro de su pecho con una multitud de imágenes, antes bien, velar para conservarse propicio, sumiso, disciplinadamente al Dios, sin mencionar una palabra contraria a la verdad, sin hacer nada contrario a la justicia. Y si todos los hombres desconfían de él, de que vive con sencillez, modestia y buen ánimo, no por ello se molesta con ninguno, ni se desvía del camino trazado que le lleva al fin de su vida, objetivo hacia el cual debe encaminarse, puro, tranquilo, liberado, sin violencias y en armonía con su propio destino. (Marco Aurelio, 180 p. 44)7

La sinergia de estos hechos con la presente crisis (se acepta generalizadamente que la actual crisis económica -con diversas opiniones sobre su origen, eso sí- surge en 2007, dura hasta hoy en mayor o menor grado, y promete mantenerse aún durante un periodo de tiempo indefinido) no es sino la que viene dada por una realidad evidente: que una sociedad -la europea y norteamericana de nuestros días- cuyas bases estructurales o "masas" (que para el marxismo eran lo único permanente en la sociedad) han estado asentadas en rentas medias8 con posibilidades económicas importantes durante mucho tiempo, no va a reaccionar revolucionariamente contra las circunstancias económicas desfavorables. No va a recurrir a la violencia generalizada ni a promover el derrocamiento forzoso de sus Gobiernos para trocarlos por instituciones distintas. Pero ¿significa esto que va a permanecer quieta y obediente mientras se le arrebata el Estado del Bienestar? ¿Ese bien de todos, que se originó en los 60 en Escandinavia y cuya exportación como modelo a todo el resto del mundo capitalista bajo el paraguas de las socialdemocracias, habla por sí misma de su capacidad como medio de redistribución de la riqueza o, al menos, como vehículo de la justicia social?. Para saberlo con certeza debemos considerar que, de acuerdo a las ideas gramscianas, más importante aún que el campo de batalla callejero o el político, es el cultural. Un entorno que en tiempos de Gramsci estaba monopolizado por la Iglesia, a través de las escuelas. Pero que ahora se ha diversificado y complicado sensiblemente con la industrialización de la cultura global y específica, y su sometimiento general, pero no generalizado, a un conjunto de intereses concretos. Me propongo determinar cuál es, verdaderamente, la vigencia de estas ideas en los Neo-marxismos

7 Aurelio, M. (ed. 1995): Reflexiones. México: Ministerio de Educación y Cultura. Disponible en: www.edu.mec.gub.uy/biblioteca_digital/libros/M/Marco\%20Aurelio\%20-

\%20marco\%20aurelio\%20meditaciones.pdf. Pág. 15.

8 En Marx no existe el concepto de clase media: está la clase trabajadora y la clase burguesa. Si que existe el concepto de renta media, que con el tiempo ha dado lugar a una concepción desideologizada de clase. Como mencionaremos más adelante, la evolución de las ideas seguramente no haría al filósofo cambiar su parecer, puesto que una generalización de las rentas medias creó la ilusión en los trabajadores de que pertenecían a esta clase; y la desaparición de estas está provocando su concienciación de que, en realidad, como asalariados, son proletarios dependientes de -sometidos a, si se prefiere- los capitalistas propietarios y empresarios. 
(habitualmente divididos en, pero no limitados a, los representantes del Marxismo Hegeliano, el Euro comunismo, el socialismo democrático, o la celebérrima escuela de Frankfurt) que se sustentan en ellas, en un entorno en que la hegemonía gramsciana ha cambiado de manos, pero no de estrato social, aunque se desarrolle en unas circunstancias sustancialmente diferentes para las masas.

\section{2.- OBJETIVOS}

Los objetivos del presente artículo se centran en conocer qué elementos del pensamiento de Gramsci perviven hoy en día dentro de los llamados movimientos de izquierdas.

Desde el marxismo, pasando por el comunismo, el leninismo, la socialdemocracia, el maoísmo, hasta el eurocomunismo, todas las ideologías existentes hoy dentro de la llamada 'gran familia de la izquierda' se nutren de avances o relecturas, que unos pensadores han ido aportando sobre el trabajo de los anteriores. Destaca, en una ideología de clase como la marxista-comunista, un pensador como Gramsci que abogaba la pedagogía ideológica, es decir, por una (re)educación desde abajo, que haga que sea la propia cultura la que encamine pacíficamente a la sociedad hacia una sociedad más justa, invirtiendo el proceso de educación capitalista que se sufre habitualmente.

\section{3.- METODOLOGÍA}

Vamos a comparar los principios distintivos y definitorios del pensamiento de Gramsci con los que alumbraron el nacimiento del Eurocomunismo. Buscaremos los puntos coincidentes entre estas dos corrientes y después buscaremos alusiones específicas que puedan desmentir este supuesto: el de que pretendidamente o no, Gramsci es el padre conceptual del pensamiento eurocomunista. Vamos a comprobar las circunstancias que rodearon al comunismo en los años 20 que llevaron al líder del PCI a desarrollar sus teorías particulares, y a determinar el porqué, hipotéticamente, estas no se generalizaron hasta casi 50 años después de su muerte. Para todo ello será imprescindible una amplia revisión y explicación de este pensamiento, y de los motivos por los que podemos considerarlo divergente de la línea oficial de Moscú.

\section{4.- DISCUSIÓN}

\subsection{El Marxismo clásico/El Gramscianismo}

Esencialmente, el marxismo habla de estructura, infraestructura y superestructura en su postulado original:

En la producción social de su vida, los hombres entran en determinadas relaciones necesarias e independientes de su voluntad, relaciones de producción, que corresponden a un determinado grado de desarrollo de sus fuerzas productivas materiales. Estas relaciones de producción en su conjunto constituyen la estructura económica de la sociedad, la base real sobre la cual se erige la superestructura jurídica y política y a la que corresponden determinadas formas de conciencia social. 
El modo de producción de la vida material condiciona el proceso de vida social, el político y lo espiritual en general. No es la conciencia de los hombres la que determina su ser, sino, por el contrario, el ser social es lo que determina su conciencia. En cierta fase de su desarrollo, las fuerzas productivas materiales de la sociedad entran en contradicción con las relaciones de producción existentes, o bien, lo que no es más que la expresión jurídica de esto, con las relaciones de propiedad en el seno de las cuales se han desenvuelto hasta entonces. (Marx 185859)9

Esta división de la realidad nos conduce a entender que la casta dominante dirige y gestiona a la Sociedad no sólo a través de la coerción, sino también mediante el recurso a la cultura, religión y positivación jurídica de su moral10.

9 Marx, K. (1989). Contribución a la crítica de la economía política. Moscú: Progreso.

10 En concepto Nietzschano la moral sería, por el contrario, una serie de normas que los seres débiles imponen a los fuertes para que no los dominen. Nietzsche, F. (1996). Genealogía de la moral. Madrid: Alianza. 
Revista de Comunicación Vivat Academia ISSN: 1575-2844

Diciembre 2014 Año XVII No $^{\circ} 29$ pp 148-170

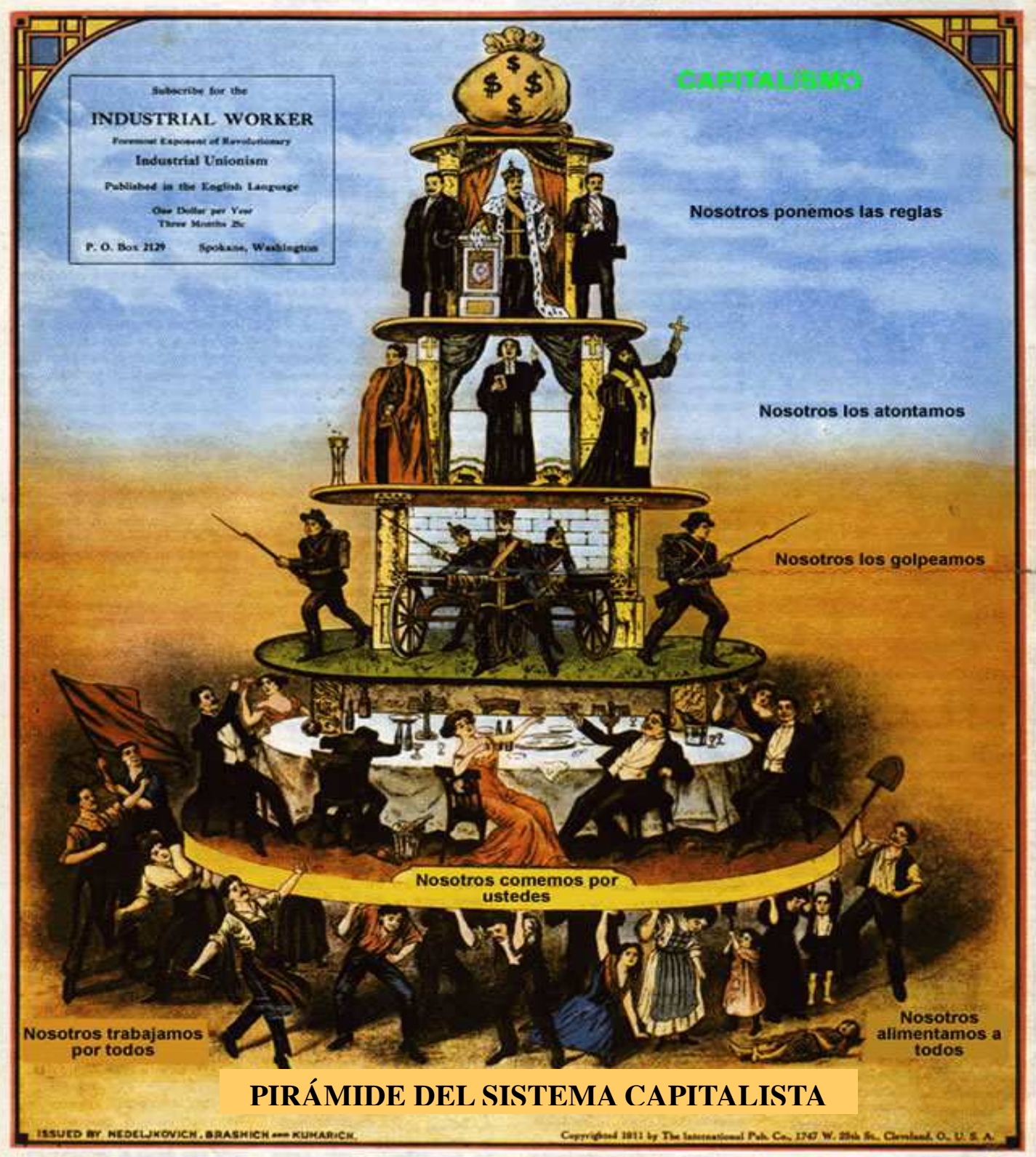

\section{Gráfico 1: La Pirámide del capitalismo}

Fuente: "Ediciones La Internacional" (1911). Disponible en: www.nuncalosabre.com/2012/03/piramide-del-sistema-capitalista.html

La Pirámide del capitalismo fue un cartel de propaganda del 1911 que tuvo mucho éxito, pues presentaba gráficamente el funcionamiento de la lucha de clases actualizado a aquellas fechas.

Hoy, la crisis actual también se ve reflejada por gráficos que tratan de pedagogizar sobre las causas y culpables de la situación de recortes en gasto social. Una vez analizado, cualquier lector puede ser educado en los valores que se pretenden inculcar. De fácil consumo, supone uno de esos elementos que configurarían la nueva cultura, derivada de la llamada 'guerra de posiciones', propugnada por Gramsci. 


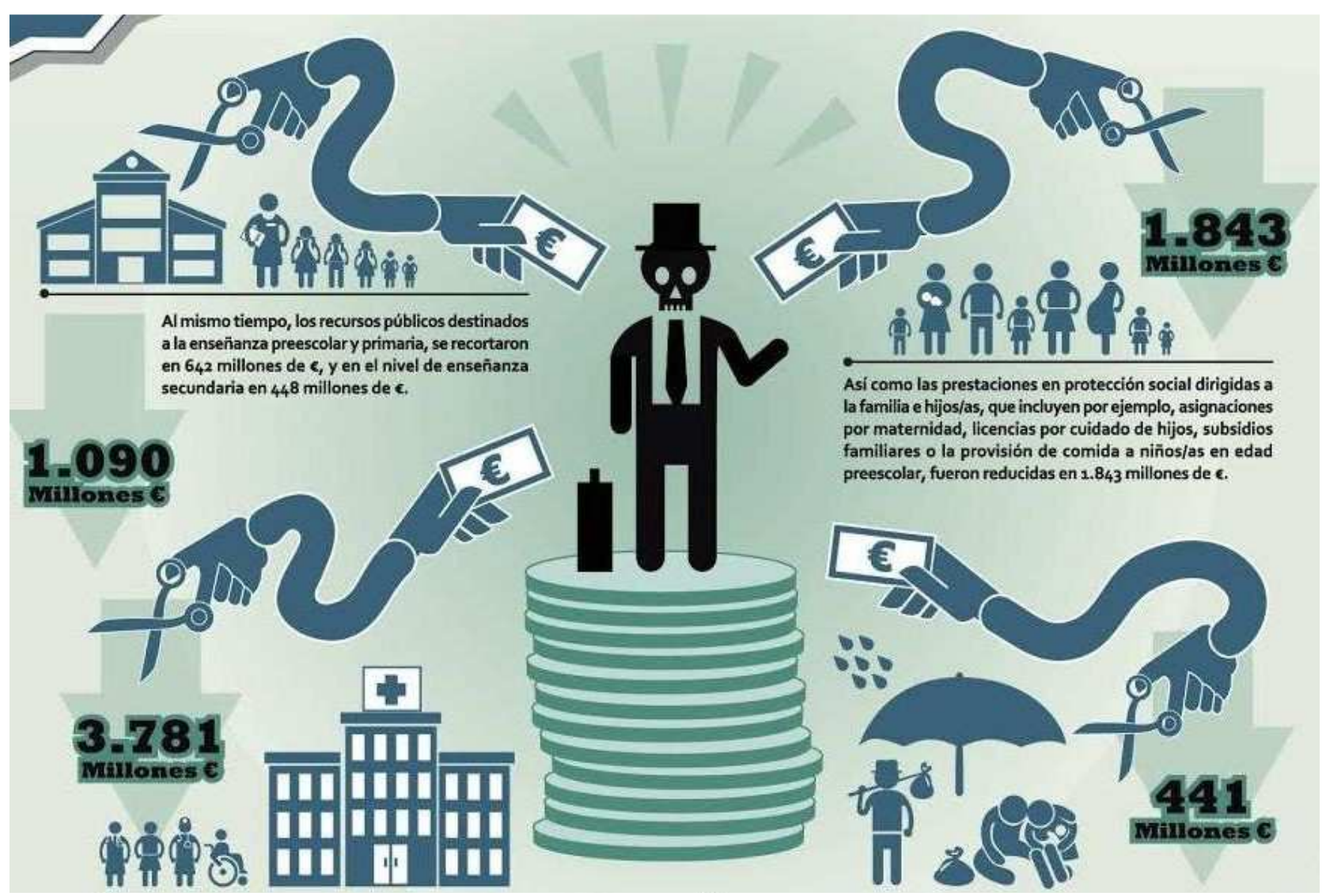

Gráfico 2: La deuda y las injerencias externas

Fuente: Diario electrónico 'De Verdad', órgano del Partido de Unificación Comunista de España.

Disponible en: $\underline{w w w}$.deverdaddigital.com

Lo correcto y bueno para dicha moral impuesta, o código concreto, se premia, mientras que lo desviado y "malo" se pune. Entre tanto, los encargados de llevar a cabo esta vindicación represora, son presentados culturalmente como jóvenes héroes patriotas y valientes, que solo buscan el bien de aquellos cuyos movimientos hacia la emancipación social tienen el deber de controlar, pues son sirvientes de una ley que obliga a todos sobre el papel, aun cuando las capas sociales pudientes tienen una mayor tendencia -facilidad- a la hora de burlarlas, en palabras de Piff ${ }^{11}$. Lo mismo ocurre con la clase dominante del momento: ya sea a través de la nobleza de sangre, del código de caballería, o del concepto de "gentleman" de la era industrial, buscan justificar su estatus social superior a través de argumentos morales, más allá de la realidad que en verdad les proporciona y permite mantener esa situación de privilegio: el control del capital y, por ende, de la producción.

Años más tarde, Gramsci, aggiornando el concepto, distingue entre dos maneras de controlar una sociedad. Esto es: mediante el dominio, que supone el sometimiento armado de la población y de cualquier fuerza que ésta pueda oponer a la represión -recurso clásico o más comúnmente concebido-; o mediante la 'hegemonía' o influencia cultural del bloque hegemónico; esto es: controlar la sociedad en cuestión gestionando, utilizando y manipulando su Cultura (¿la nueva superestructura en términos de marxismo clásico?) y sus referencias morales, de modo que sea la propia educación de los sujetos la que les haga

11 Piff, P. K. (2012). Higher social class predicts increasing unethical behaviour. Berkeley: Berkeley University Press. 
"saber" como dato evidente, que el presente estado de cosas es el correcto, y que es inconveniente, e incluso perjudicial para ellos -los interesados- cambiarlo o variarlo, sobre todo de manera violenta. Como dijera acertadamente Marshall McLuhan: el medio es el masaje12. La idea no es nueva, como muchas otras en la historia del pensamiento: ya en tiempos de los romanos, el control de la información que llegaba al pueblo era un mecanismo de sojuzgamiento: pues sabían que el que escribe la primera historia de un hecho, escribe todos los libros de historia posteriores al respecto13. Un principio también valedero para las adaptaciones, obras teatrales, versiones, novelas y canciones: todas ellas herramientas de difusión del conocimiento sobreexplotadas por la actual hegemonía. Mediante este sistema se apuntaló un imperio de mil años y a su aristocracia dirigente, que nunca fue verdaderamente relevada del poder.

Otro punto de señera importancia, es que Gramsci apreció diferencias entre la casuística revolucionaria contemporánea ruso-soviética y la europea -lo que le enlaza con quienes años después adujeron, por su parte, incompatibilidades atribuibles en muchos casos, al distinto marco teórico de desarrollo social- en el primero ha sido posible una "guerra de movimiento" (haciendo con ello analogía de la revolución violenta, inmediata, de nuevo: clásica; con una referencia tanto al tipo de guerra que se había practicado durante las primeras fases de 1914, como a las teorías militares de "Guerra Celere" o guerra rápida que surgieron después de la firma del tratado de Versalles) mientras que en el resto del viejo continente es -era- preciso un enfoque más pausado o de "guerra de posiciones" (o "de trincheras" según se localice la traducción; de nuevo un ejemplo basado en el horrible tipo de guerra que había estado asolando el continente hasta 1918, pero que probablemente tenía una connotación menos melodramática en los países que, como Italia, pertenecían al bloque vencedor; sería este un enfrentamiento en el terreno cultural, necesariamente más lento que la toma del poder por la fuerza, pero más efectivo a largo plazo) pese a lo cual, basa sus propuestas en el pensamiento de Lenin, por considerar que ha dado en entender el verdadero concepto de 'hegemonía':

El máximo aporte de Ilich [por Lenin] a la filosofía marxista [...] la realización de la 'hegemonía' significa la crítica real de una filosofía, la puesta en marcha de su dialéctica real dentro de la doctrina y la práctica política. (Gramsci, 1929-32)14

Quizá una concesión al oficialismo del partido en aquel momento, puesto que Lenin también fue el artífice de la revolución rápida. Para Gramsci, fue la especial coyuntura rusa, y la desacertada política Zarista15 la que permitió acelerar la llegada de los bolcheviques (en su étimo 'mayoritarios', por ser la más numerosa tendencia del partido revolucionario) al poder (es significativo en todos los aspectos recordar que, durante los

12 McLuhan, M. (2011). El medio es el masaje. Paidós. Barcelona. En esta obra, McLuhan entra al trapo del juego de Joyce en "El Ulises" en el que la forma del lenguaje es más importante que el contenido mismo. El juego de palabras viene de las palabras inglesas "Mensaje" (Message) y "Masaje" (Massage) casi indistinguibles, y más aún en términos de pronunciación. Toda la obra está salpicada de perlas similares.

13 Churchill, Winston: "La historia será amable conmigo, porque tengo intención de escribirla"

14 Gramsci, A. (ed. 1975). Cuadernos de la cárcel (vol. I). Turín: Einaudi. Pág. 464-465.

15 Nos referimos, claro, a la represión del Domingo Sangriento. Bien es cierto que fue el gran duque Aleksándrovich quien tuvo la nefasta idea de ordenar abrir fuego contra los manifestantes del palacio de invierno, pero Nicolás II no tenía motivos tampoco para simpatizar con los revolucionarios, que habían asesinado al aperturista Alejandro II. 
dramáticos acontecimientos que rodearon a la toma del palacio de invierno, hoy museo Hermitage, el propio Lenin confesó que todo aquello le producía vértigo16) Explica Gramsci las razones de esta diferencia fundamental, en cierta forma, en sus opiniones sobre Nicolás Maquiavelo:

El moderno Príncipe, el mito-Príncipe, no puede ser una persona real, un individuo concreto; sólo puede ser un organismo, un elemento de sociedad complejo en el cual comience a concretarse una voluntad colectiva reconocida y afirmada parcialmente en la acción. Este organismo ya ha sido dado por el desarrollo histórico y es el partido político: la primera célula en la que se resumen los gérmenes de voluntad colectiva que tienden a convertirse en universales y totales. En el mundo moderno sólo una acción histórico-política inmediata e inminente, caracterizada por la necesidad de un procedimiento rápido y fulminante, puede encarnarse míticamente en un individuo concreto. La rapidez se torna necesaria solamente cuando se enfrenta un gran peligro inminente que provoca la inmediata exacerbación de las pasiones y del fanatismo, aniquilando el sentido crítico y la corrosividad irónica que pueden destruir el carácter "carismático" del condottiero (Gramsci, 1932)17

Es decir: la profunda emergencia nacional, la guerra, la derrota, la inestabilidad, el hambre, la represión... todo ello se aúna para que un pueblo -el ruso en este caso- se replantee la hegemonía preponderante del Zar y la Iglesia ortodoxa, y se lance en brazos de la contra-cultura, representada, en suma, por aquel que sea capaz (o diga serlo) de resolver los problemas acuciantes del país. El sistema tradicional para la imposición de dictaduras personales (recordamos de nuevo a los romanos, y también a los Tiranos Griegos) empleado para imponer la de un partido.

Sin una emergencia o gran crisis que evidencie los defectos del sistema capitalista/aristocrático (según el caso) y de su hegemonía ante los ciudadanos, catalizando el proceso revolucionario, este no puede precipitarse, luego es preciso socavar la base hegemónica de las clases dominantes de manera gradual, sin recurrir a la violencia y a la agitación callejera, sino a las escuelas y al diálogo con los sectores descontentos.

\section{2.- El Cambio de Marco Social de los 70}

El recientemente fallecido Secretario General del PCE, Santiago Carrillo, fue uno de los grandes impulsores del nuevo Eurocomunismo, junto a comunistas italianos -para los que la figura de Gramsci estaba más presente- y franceses. En su último libro "Eurocomunismo y Estado" el fumador más incorregible de la política Española recuperaba abiertamente el término "Hegemonía" aunque sin ahondar mucho en su origen:

...las nuevas concepciones de la vía al socialismo en los países desarrollados comportan ciertas matizaciones sobre el papel y la función del PCE. El partido no

\footnotetext{
16 Deutscher, I. (1967). Stalin: A Political Biography. Oxford: Oxford University Press. "Lenin confesó irónicamente una sensación de mareo causada por esa transición, después de quitarse el maquillaje, la peluca y las grandes gafas, y sentirse gobernando al gran estado Ruso".

17 Gramsci, A. (ed. 1975). Cuadernos de la cárcel (vol. I). Turín: Einaudi. Pág. 464-465.
} 
propone convertirse en la fuerza dominante del Estado y la sociedad, ni imponer su ideología a éstos con carácter oficial. La misión del partido, es contribuir a que las fuerzas del trabajo y de la cultura conquisten la hegemonía político-social. Por eso, el partido no aspira a conquistar el poder para él, monopólicamente, sino a un poder en el que participen y cooperen, según su peso real, los diferentes grupos políticos representativos de esas fuerzas, en una emulación por el progreso, el socialismo y la democracia ${ }^{18}$.

En este libro, sin ignorar la figura de Gramsci, el mítico comunista hace referencia a este meramente en aspectos económicos, y no en los fundamentos de la nueva ideología. También señala la invasión de Checoslovaquia como el momento clave en la "independencia" de los partidos europeos. No era este sino el último y el penúltimo peldaño en una escalada que debía producirse entre un partido sin contestación social alguna, inmerso en la realidad soviética, y otro grupo de partidos que debían responsabilizarse ante opiniones públicas críticas y hasta hostiles cada vez que Moscú implementaba una política radical. Partidos estos que, además, estaban inmersos en realidades sociales muy distintas a las existentes al otro lado del muro, y que sentían que debían adaptarse a esas realidades en vez de a las pautas rusas. Porque si a Gramsci le preocupaba la preeminencia eclesiástica en la educación y la cultura, apoyada en masas campesinas reaccionarias que ella misma creaba, retroalimentándose; desde el final de la segunda guerra mundial es la generación de cultura en su conjunto -y no principalmente la educación religiosa- la que se ocupa de crear el conformismo social imperante. El arte escultórico y pictórico se vuelve progresivamente inasequible al ciudadano medio, abstrayéndose y centrándose en el objetivo de transmitir "sensaciones" o "sentimientos" en lugar de mensajes o compromisos. El cine y la televisión desplazan al teatro a un puesto marginal de influencia social, y sustituye el entretenimiento de masas tradicional por un mercado, donde predominan los productores más poderosos, mayoritariamente judíos como Marx, -quienes crearon una gran industria en el país garante del nuevo orden mundial [novus ordo seclorum, como reza el billete del dólar] y social de la Pax americanaTal como vieron Theodor Adorno y Max Horkheimer, de la Escuela de Fránkfurt:

El placer se petrifica en aburrimiento, pues, para que siga siendo placer, no debe costar esfuerzos y debe por lo tanto moverse estrechamente a lo largo de los rieles de las asociaciones habituales. El espectador no debe trabajar con su propia cabeza: toda conexión lógica que requiera esfuerzo intelectual es cuidadosamente evitada. (Adorno y Horkheimer 1947)19

Un concepto que, en nuestro tiempo, se identifica con la creación de grandes programas televisados de contenido intrascendente y duración desmesurada, que embelesan a grandes masas de televidentes. Hablaron también sobre el entretenimiento destinado a los más jóvenes:

La hilaridad quiebra el placer que podría proporcionar, en apariencia, la visión del

18 Carrillo, S. (1977). Eurocomunismo y Estado. Madrid: Crítica.

19 Adorno, T. y Horkheimer, M. (1988). La industria cultural. Iluminismo como mistificación de masas. Buenos Aires: Sudamericana 
abrazo, y remite la satisfacción al día del pogrom. Si los dibujos animados tienen otro efecto fuera del de acostumbrar los sentidos al nuevo ritmo, es el de martillar en todos los cerebros la antigua verdad de que el maltrato continuo, el quebrantamiento de toda resistencia individua,l es la condición de vida en esta sociedad. El Pato Donald en los dibujos animados como los desdichados en la realidad recibe sus puntapiés a fin de que los espectadores se habitúen a los suyos (Adorno y Horkheimer 1947) 18

Un rápido vistazo a las producciones de cine y animación de la época a la que hacen referencia estas alusiones citadas (los años 50) basta para ver la saturación del humor basado en la violencia. Una tendencia que no se ha extinguido, pero si se ha moderado, o especializado, en series de animación no eróticas para público maduro: con la industria audio-visual europea sumida en las producciones de autor y en las series de consumo nacional, Estados Unidos y Japón (con su poderosa industria de animación y ocio electrónico) son los dos grandes creadores de contenidos culturales de entretenimiento. Y son los valores de la democracia americana -un país donde el marxismo y el socialismo son recurrentemente utilizados para "disuadir" al público de apoyar según qué medidas pasadas y presentes20- los que estas industrias vuelcan a la sociedad mundial globalizada, de manera mayoritaria y permanente. Ésta es, pues, la nueva hegemonía de nuestro tiempo.

Incluso con la aparición de Internet, un medio creado a partir de infinitas fuentes, difícil y farragoso de controlar y que, por vez primera, haría hipotéticamente posible la democracia directa que tanto inspiró a Marx en la comuna de París (18 de marzo - 28 de mayo de 1871); la potencia de estos dos grandes emisores culturales en el campo del ocio electrónico está haciendo que la contracultura neo-marxista -cualquier contracultura, de hecho- encuentre cobijo pero no hegemonía en este medio. Salvo, claro está, que entendamos como tal el fenómeno de "cultura gratis" que ha generado la piratería digital nacida al calor de este efervescente intercambio libre de datos. Pues por un lado, este caso social ayuda igualmente a difundir los productos de la industria cultural predominante, pero por otro, atacan sus bases de financiación, así como las del propio sistema que ayudan a perpetuar, dando, en cierta medida, valor al determinismo de Marx y su teoría de que el sistema capitalista está abocado a caer por sus propias contradicciones intrínsecas. Solo medidas comunistas salvaron la economía de EEUU en la crisis del 29, gracias a la nacionalización de los bancos y el crecimiento del sector público.

Volviendo a Gramsci, recordamos que sus conclusiones al respecto de la 'hegemonía', marcan la diferencia -que ya hemos citado- entre el caso ruso (guerra de movimiento, $\mathrm{u}$ obtención inmediata del poder mediante la acción revolucionaria) y el caso de las naciones plenamente industrializadas (prototípicamente Italia) en el que habría que llegar al triunfo socialista mediante una "guerra de posiciones". Un enfrentamiento más lento y metódico, además en un campo de batalla sensiblemente distinto. Si la revolución rusa se libró con fusiles y arengas en las calles, la lucha de la que hablaba y por la que avocaba Gramsci habría de desarrollarse en las escuelas y los centros sociales, con libros, con propaganda y con diálogo, en el ámbito cultural. Su objetivo no sería vencer para convencer, recordando al maestro Unamuno, sino al revés: ganar la batalla de la hegemonía ideológica social, una 
vez logrado lo cual, las ideas de Marx sobre lo inevitable de la revolución se harían necesariamente realidad, al ser compartidas globalmente llegada la derrota de la hegemonía cultural burguesa pre-existente, cuyo mayor éxito ha sido siempre controlar el presente para elaborar el pasado y dominar el futuro.

Ya de joven me había fijado en que ningún periódico cuenta nunca con fidelidad cómo suceden las cosas, pero en España vi por primera vez noticias de prensa que no tenían ninguna relación con los hechos, ni siquiera la relación que se presupone en una mentira corriente. (...) En realidad vi que la historia se estaba escribiendo no desde el punto de vista de lo que había ocurrido, sino desde el punto de vista de lo que tenía que haber ocurrido según las distintas «líneas de partido». (...) Estas cosas me parecen aterradoras, porque me hacen creer que incluso la idea de verdad objetiva está desapareciendo del mundo. A fin de cuentas, es muy probable que estas mentiras, o en cualquier caso otras equivalentes, pasen a la historia. ¿Cómo se escribirá la historia de la Guerra Civil Española? (...) Sin embargo, es evidente que se escribirá una historia, la que sea, y cuando hayan muerto los que recuerden la guerra, se aceptará universalmente. Así que, a todos los efectos prácticos, la mentira se habrá convertido en verdad. (...) El objetivo tácito de esa argumentación es un mundo de pesadilla en el que el jefe, o la camarilla gobernante, controla no sólo el futuro sino también el pasado. Si el jefe dice de tal o cual acontecimiento que no ha sucedido, pues no ha sucedido; si dice que dos y dos son cinco, dos y dos serán cinco. Esta perspectiva me asusta mucho más que las bombas, y después de las experiencias de los últimos años no es una conjetura hecha a tontas y a locas. (Orwell, 1939)21

El fiscal que condenó al fundador del Partido Comunista Italiano, habló sobre la necesidad de "silenciar a este cerebro durante veinte años"22 Esta declaración puede deberse a la comprensión de que el Partido Nacional Fascista de Italia (PNF) había concebido su dialéctica y sus estructuras para combatir una revolución violenta como la bolchevique en la Unión Soviética. El enfrentamiento físico les convenía, el intelectual propugnado por Gramsci no, tal como dejó claro el escándalo Matteotti: el caso de un célebre diputado socialista que pronunció un duro discurso contra Mussolini en sus primeros años de gobierno, y que remató con un "Yo ya he hecho mi discurso. Ahora os toca a vosotros preparar el discurso fúnebre para mi entierro"23. Contrariamente a cuanto dictaba la lógica en lo respectivo a las relaciones públicas de los fascistas, Giacomo Matteotti fue asesinado diez días después, y hallado muerto en una cuneta a los dos meses. El gobierno de Mussolini casi cayó por aquello: una cosa era que la milicia del partido (los camisas-negras) atacasen a los huelguistas y a los comunistas de base, fácilmente identificables con el deterioro político del país y declaradamente contrarios a la hegemonía cultural de la que culpaban a la Iglesia. Pero al moverse contra Matteotti, le dieron la razón en sus denuncias.

Así pues, tenemos una masa ciudadana abocada al pensamiento de la clase media, pero a

21 Orwell, G. (1978). Mi guerra civil Española. Madrid: Destino. Haciendo referencia al mensaje contenido en Orwell, G. (1948). 1984. Londres: Signet.

22 "Debemos impedir a este cerebro funcionar por veinte años" expresó Michelle Isgrò, Fiscal del Ministerio Público en el proceso donde se juzgaba a Gramsci y a otros dirigentes comunistas italianos. Actas del juicio. 23 Cyaheled, L. (1924). Matteotti è vivente. Nápoles: Vedova Ceccoli \& Figli. 
la que la crisis, el paro, y la sub-remuneración empujan a una suerte de lucha o al menos de desquite en el terreno cultural, proporcionada por los nuevos espacios de relación creados en Internet. Un entorno nuevo que, además, facilita la difusión de la contracultura, si entendemos por ella la reflexión crítica e individualizada sobre la sociedad, aunque no esté ligada intrínsecamente a ninguna ideología, ni siquiera a la meramente jacobina, pues estamos hablando incluso de formas de contracultura que no buscan una revolución en sí, sino, por ejemplo, la aplicación igualitaria de las leyes existentes. Aún cuando este solo objeto pueda considerarse subjetivamente lo bastante ambicioso como para ser tenido por una idea del partido de Robespierre.

Esta contracultura "mixta" o heterogénea se ejecuta a través de todo tipo de medios: páginas y blogs personales, web profesionales, bitácoras, foros de discusión en los que verdaderos debates muy bien documentados quedan registrados puntualmente, correspondencia electrónica, mensajes telefónicos breves... cada vez que una causa llama a la denuncia (o, para ser enteramente justos, también cada vez que se desea tornar una causa en objeto de censura pública, sea ésta justificada o no) los sujetos individuales tienen una capacidad muy similar a la de las empresas y los partidos políticos para hacerse eco de ello en sus propios medios digitales. Aquellos dotados del talento de la buena literatura, o de la creación de imágenes populares, reciben el mayor número de visitas y pueden dar su propia interpretación de la realidad a un mayor número de individuos, creando, poco a poco, una contra-cultura, en el sentido de que es una tendencia distinta a la oficial, que reclama al sistema que cumpla sus promesas o caiga en el intento. Importantes iniciativas evidencian esta realidad: páginas como "Change.org"24 se han creado con el único fin de concretar esta plataforma para que la propia sociedad pueda hacerse oír ante la política y los medios de comunicación, facilitando la reunión de firmas y apoyos para proyectos, iniciativas legislativas populares, solicitudes diversas, etc. También las cada vez más abultadas agendas de contactos de los jóvenes convierten la telefonía móvil (o inteligente) en una herramienta, si no de reunión, si de difusión masiva de cualquier acontecimiento, injusticia, noticia o idea que un ciudadano haya presenciado en un momento dado. Hoy por hoy, la misma persona puede poner sobre aviso a varias decenas sobre un hecho, narrarlo en detalle y además aportar pruebas fotográficas cada vez más nítidas, todo con el mismo dispositivo. Cuando a todo esto le sumamos la generalizada enseñanza del inglés, que permite, como lengua franca, la comunicación entre individuos de nacionalidades y culturas muy diversas, el resultado es la globalización humana: la unión de los individuos antes que la de los centros ejecutivos. El acercamiento de personas muy alejadas entre sí, la posibilidad que esto da de contrastar información de carácter internacional al margen de los grandes medios de comunicación públicos o privados, y la posibilidad de realizar libres intercambios no económicos a una escala nunca vista, sobre todo en materia de servicios y de productos digitalizables.

Este nivel creciente de relación, ya fue apreciado por Marx, y previsto -no podemos decir que en su totalidad sin caer en lamentables hipérboles hagiográficas- como un factor determinante en su futuro.

El verdadero resultado de sus luchas (las de los obreros) no es el éxito inmediato, sino la unión cada vez más extensa de los obreros. Esta unión es propiciada por el 
crecimiento de los medios de comunicación. (...) La gran industria ha creado el mercado mundial, ya preparado por el descubrimiento de América. El mercado mundial acelera prodigiosamente el desarrollo del comercio, de la navegación y de los medios de transporte por tierra. (Marx y Engels, 1848)25

Precisamente porque entendieron la necesidad de presentar una batalla efectiva en el terreno cultural, los neo-Marxismos son importantes en este nuevo contexto: tanto el eurocomunismo como el socialismo democrático vieron más pronto o más tarde, los fallos y las incongruencias fundamentales del modelo soviético (principalmente todo lo relacionado con el mal estado de los derechos humanos dentro de sus fronteras)

Stalin lanzó al Partido y la N.K.V.D. [Comisariado del Pueblo para Asuntos Internos, precursor del KGB] a una política de terror cuando las clases explotadoras de nuestro país habían sido liquidadas, por lo cual no había razón que la justificara. Este terror tenía como objeto no eliminar los restos de las clases explotadoras, sino perseguir a trabajadores honrados del Partido y del Estado Soviético; contra ellos se esgrimieron acusaciones difamantes, falsas y absurdas, atribuyéndoseles intenciones ocultas de espionaje, sabotaje y la preparación de complots ficticios, etc. (Jrushchov, 1956)26

En 1973, Solzhenitsyn publicó, además, lo que había podido salvar de Archipiélago Gulag porque el resto del manuscrito cayó en manos del KGB (Comité para la Seguridad del Estado, por sus siglas en ruso). Un material que comprendía declaraciones de más de 200 supervivientes de campos soviéticos de prisioneros, viniendo de un escritor que ya había denunciado la acción de la censura bolchevique sobre sus obras, ayudó a Occidente a entender mejor el día a día al otro lado del muro. En este caso, el Partido creyó que bastaría liberar al escritor para ganárselo, cuando en realidad habían perdido hacía mucho tiempo la posibilidad de traerlo a su causa, y no había forma en que pudieran ejercer coerción sobre él para que dejara de pensar de esa manera.

Los partidos neo o euro-comunistas comprendieron que tener a la URSS detrás para ayudarles a luchar en el terreno revolucionario, no podía hacer que descuidaran el campo de batalla cultural: la lucha por los corazones y las mentes de la población, que Estados Unidos ganaba con facilidad por aquel entonces, gracias a su superior industria cultural, pero también a las pésimas decisiones -para su imagen pública- de la URSS, como la intervención militar del Pacto de Varsovia que acabó con los hechos conocidos hoy como la Primavera de Praga. Aquel movimiento disparó, de hecho, los movimientos eurocomunistas27 y un Soviet Supremo que, temeroso de cualquier cambio, o de un nuevo Nikita Jrushchov, acabaría manteniendo en el cargo de Secretario General casi a la fuerza al anciano Leónidas Breznev, no era el que iba a reconocer sus errores y a felicitar a aquellos partidos europeos por su iniciativa e independencia ideológica. (Acallándose las voces disidentes de Alexander Dubček, Josef Smrkovský, Oldřich Černík, y Frantisek Kriegel; pero ignorándose también las enérgicas protestas de los partidos comunistas

25 Marx, K. \& Engels, F. (2012). El manifiesto comunista. Barcelona: Nórdica libros.

26 Kruschev, N. (2010). Informe Secreto, en Cuadernos Socialistas. Pág. 36.

27 Se sabe que muchos ilustres comunistas, incluido Jean-Paul Sartre, rompieran sus carnets del Partido a raíz de aquellos hechos. 
Italiano, Francés, Español y Finlandés, así como una importante parte del Partido Comunista Griego, y de varios manifestantes soviéticos que fueron detenidos en la Plaza Roja con pancartas que rezaban "Por su libertad y la nuestra")

A otro tanto se sumaron Olin Wright, Elster y Cohen cuando fundaron el marxismo analítico -no olvidemos- sobre la base de su propio grupo de pensadores, denominado "Marxismus sine stercori tauri" o "Marxismo sin excrementos de toro" y dando a luz una concepción individualista del marxismo: una ideología considerada de -y- para masas $u$ holística por excelencia, que ahora reconocía el valor de lo humano y lo personal como elemento constituyente del todo. Un reconocimiento necesario para llegar hasta lo más profundo de las convicciones culturales del occidente europeo:

Los occidentales viven en sociedades más independientes, focalizadas en la realización de los objetivos personales mientras que para los asiáticos la causa de todo está en el contexto (Masuda, 2012)28

En el origen de todas estas tendencias reconocemos a Gramsci, Lucasz, y el marxismo hegeliano, que reconocen la futilidad del determinismo: el convencimiento de que la sociedad capitalista está abocada a caer por sí sola. Así, mientras ellos llamaban a la acción para precipitar ese derrumbe, casi cincuenta años después los primeros comprendían al fin lo que Gramsci había expresado hablando sobre la guerra de posiciones: la acción no violenta, en el terreno cultural y educativo. Una lucha paciente y consistente, emparentada con la necesidad racional de avanzar como sociedad, y no con la emoción animal de destruir físicamente al llamado "enemigo de clase". En resumen: convencer para vencer.

No faltaron las voces en ambos lados que, a la caída de la URSS, entonaron el socorrido cántico "Ya se veía venir". Aplicando el aforismo latino "Post hoc ergo propter hoc" ("Después de esto, por lo tanto, a consecuencia de esto") del mismo modo que quienes entonan el fracaso económico del comunismo cubano (olvidando convenientemente el papel desempeñado por el bloqueo estadounidense) al mismo tiempo proclaman su temor y reverencia al poder y las riquezas de China, omitiendo de forma aun más conveniente la naturaleza de su sistema social. Quienes entonaron este mantra olvidan asimismo el empeño de la administración Reagan, que comenzó una carrera de armamentos que en nada benefició a la economía norteamericana, con el exclusivo propósito de forzar a los soviéticos a seguirles, llevándoles al colapso financiero -algo de difícil encaje en un modelo de moneda no convertible-. Si algo se veía venir, era la reducida proporción de habitantes que lloraría a la Unión Soviética fuera, e incluso dentro de sus fronteras en caso de caer ésta. Y eso se debe, ni más ni menos, a la derrota en el combate por los corazones y las mentes que Moscú había desatendido. De los occidentales pero también de muchos rusos, ucranianos, etc... cuya experiencia vital y familiar les decía que, en el fondo, sonaba bien la perspectiva de que el Estado no estuviera tan presente en las vidas de los ciudadanos. La dictadura del proletariado se había convertido en la del Partido, al igual que en la democracia, el poder del pueblo, seguía siendo en mucha medida el poder de los políticos y los empresarios. (Ya hemos aludido a Reagan antes, en relación a sus opiniones sobre la socialización de la medicina. Unas opiniones que, si fueran ciertas, significarían que la

28 Sandri, P. M. (2012). ¿En qué pensamos distinto los occidentales de los orientales?, en La Vanguardia Digital. Disponible en: www.lavanguardia.com/estilos-de-vida/20120302/54262328877/en-que-pensamosdistinto-los-occidentales-de-los-orientales.html 
URSS ganó la guerra fría, porque Europa entera es ferozmente comunista cuando el criterio para determinarlo es si existe o no medicina socializada en sus países integrantes) La primera de las batallas en la guerra cultural, podrían estarla ganando las mujeres desde hace décadas, con una guerra de posiciones tan lenta y metódica que casi nadie ha advertido su carácter social. Ya preveía Marx en El Capital que la otra revolución pendiente era la de la mujer. Cuyo trabajo no estaba siquiera remunerado, y constituía un regalo para el patrono, que contaba inconscientemente con madres y esposas fieles para mantener a sus obreros y administrar sus escasos salarios. El feminismo notablemente, y quizá por estar alejado en lo estético de la lucha de clases para constituir la lucha -o liberación- de sexos, ha tenido un mayor eco en los medios modernos, mucho antes de la llegada de Internet; apoyado por el gran impulso que supusieron las pruebas de fuego de ambas guerras mundiales, donde las mujeres desbarataron el aparato de prejuicios sexistas pre-existente trabajando en la industria pesada y hasta luchando en el frente (tanto en los organizados batallones rusos, como en los caóticos y escasos reemplazos británicos de 1918). Pero ese éxito no ha tenido -ni parece que vaya a tener- carácter revolucionario. La costumbre -el papel social asignado a la mujer- tampoco ha cambiado realmente: tan solo (lo que ya es mucho) la fuerza coercitiva con la que se impone, que en nuestros días se haya severamente restringida, o incluso perseguida; y la rigidez de miras social que a este particular se aplicaba hace tan solo media docena de décadas. "Las proletarias de los proletarios" no se han emancipado en el sentido total del término, pero han ganado el derecho a ser escuchadas y el derecho a renegociar -en su totalidad si así se tercia- todos los términos del contrato social doméstico con su pareja, compañero o incluso hijos. Todo ello se ha logrado mediante un esfuerzo continuado y constante de influencia cultural y educativa, cuyos únicos episodios verdaderamente violentos -la constatación en ambas guerras mundiales y en la revolución rusa de que las mujeres pueden fabricar armas modernas y utilizarlas en campaña como cualquier varón- ni siquiera han sido motivados por este mismo movimiento.

Como la actual masa social, Gramsci venía de un entorno peculiar, en tanto en cuanto no era fácilmente clasificable socialmente. La obra de Gramsci debe entenderse sabiendo esto, y que se divide en dos periodos: su producción periodística y sus cuadernos de la cárcel. Siendo los últimos los más importantes y debiendo asumir que el nivel de documentación de los mismos no puede alcanzar al de los textos investigativos de Marx, por la diferente calidad de los tomos disponibles en una cárcel italiana y en el museo británico, respectivamente. Sin embargo, él hablaba desde un conocimiento más meditado de la realidad obrera de Europa occidental. Pues si bien, su dialéctica no pretendió nunca ser lo que fue la de otros contemporáneos -todo político de la época palidece ante la inequitativa situación de tener que competir ante los micrófonos con Churchill y sus homólogos fascistas- si que podría compararse su atención al medio escrito de cara al obrero, con el mayor de los esfuerzos propagandísticos de su época. Fiel a sus propias ideas sobre el frente cultural de la revolución, fue, entre otras cosas, fundador del semanario "L'Ordine nuovo" por el que el público obrero sentía predilección ya qué, según el propio Gramsci "los artículos no eran frías arquitecturas intelectuales, sino que desobstruían nuestra discusión con los mejores obreros, creaban sentimientos, voluntad, pasiones reales de la clase obrera turinesa [...] eran casi una toma de conciencia de sucesos reales" (Gramsci, 1939) Una publicación subtitulada "Reseña semanal de cultura socialista" que, tras la guerra del 14-18, pretendía precisamente eso: hacer entrar más en contacto a los intelectuales de "la vanguardia del 
proletariado" y a sus ideas, con las bases que debían sostenerlos y a las que su mensaje iba dirigido.

Años después, el auge de la socialdemocracia en Europa desde la caída de la URSS demuestra que un marxismo compatible con las libertades y el individualismo es posible. El dirigente del Partido Comunista de España, Santiago Carrillo, ya adelantó cuando, en los 70, Moscú condenaba sin pábulo el recién nacido euro-comunismo, que muchas de las tesis de Lenin de 1917 y 1918, aplicables a la realidad rusa de aquella época y de otros lugares del mundo de entonces, resultaban inadecuadas en los países capitalistas desarrollados de Europa occidental. De hecho el Eurocomunismo preconiza la extinción de tres pilares básicos: 'el partido único' (pues acepta la democracia), 'la dictadura del proletariado' (pues acepta el cambio en el gobierno a partir de elecciones libres) y la 'revolución proletaria' (al acercarse a las rentas medias). Su inadecuación se debía, fundamentalmente, a las estructuras económicas y la conducta objetiva de los grupos sociales progresistas, al desarrollo de las nuevas fuerzas productivas - como la energía nuclear- y a otras muchas circunstancias que, como era lógico, escaparon a la consideración de los ideólogos marxistas del siglo XIX y de las primeras décadas del siglo XX. Volvemos a ver aquí a Gramsci, y su percepción de que el modelo ruso no era directamente exportable ni a su país ni a ninguno del área inmediata.

El advenimiento de la crisis económica ha causado que las propuestas socialdemócratas -a fin último, las arquitectas del estado europeo del bienestar- empiecen a perder fuerza ante el electorado como válvula de escape moderada a la lucha de clases, apelando ser la única representación obrera no violenta y redefinirse como voto de izquierdas (tras el choque en la II Internacional de 1889 y el vilipendio a esta ideología -heredera lejana ya del marxismo- por parte de cabecillas socialistas y comunistas ortodoxos, como Stalin29 verdadero vencedor en la III Internacional). Esto se debe en buena medida a un efecto péndulo causado por factores económicos en la mentalidad popular: mientras la actividad laboral se mantuvo, y el crédito fluyó, el nivel de vida de los trabajadores y asalariados les hizo instalarse en la creencia de que se encontraban situados en la comodidad social de la clase media. Con la subida del paro y la cada vez más difícil situación económica, unida a la intercomunicación mediante redes sociales, que permite al ciudadano constatar "por si mismo" la gravedad de los hechos; se ha producido un súbito renacer de la conciencia obrera (de la conciencia de que se es obrero mientras se sea asalariado): la crisis como motivación, y los nuevos medios de comunicación como canal, potencian el activismo y la lucha contra las clases políticas y oligárquicas, generalizadamente consideradas responsables del desastre. $Y$ lo hacen al margen de organizaciones y medios tradicionales, como los sindicatos. Sobre todo en sociedades donde estos han terminado siendo considerados popularmente como parte del problema, como revelan, entre otros datos, las bajas cifras de afiliación30.

29 A Stalin se le atribuye un feroz odio a las socialdemocracias, que puede ser constatado en frases suyas como: "No se puede acabar con el capitalismo sin acabar con la ideología socialdemócrata en el movimiento obrero" o "El fascismo es la organización de combate de la burguesía que se apoya en el respaldo activo de la socialdemocracia. La socialdemocracia es objetivamente el ala moderada del fascismo. No hay bases para asumir que la organización de combate de la burguesía pueda lograr éxitos decisivos en las batallas, o en el gobierno del país, sin el apoyo activo de la socialdemocracia... Esas organizaciones no se niegan entre sí, sino que se complementan mutuamente. No son antípodas, son gemelos. El fascismo... existe para combatir la revolución proletaria". Frases recogidas en: http://es.wikiquote.org/wiki/I\%C3\%B3sif_Stalin.

30 Según datos del CIS en noviembre de 2013, los españoles prefieren el asociacionismo civil, cultural o 
Sin embargo, esas mismas tecnologías y los factores culturales de individualismo comprendidos e incluidos por los neo-marxistas en sus entramados teóricos, hacen que el nuevo activista tienda más a considerarse en la dimensión de "ciudadano" que en la clasificación de "obrero" (aún cuando efectivamente lo sea) pues se siente más definido por sí mismo que por su trabajo -al fin y al cabo, una necesidad vital, y no un fin por sus propios méritos, citando a Lafargue31- haciendo que la lucha obrera del siglo XXI se torne súbitamente, casi por generación espontánea, en la lucha propuesta por Antonio Gramsci en los años 20: una pugna pacífica por el alma y la mente de la sociedad, en los campos de batalla culturales. La interconexión de esta moderna "Masa revolucionaria" le permite mantener esa identificación basada en el ocio además de en el trabajo (ocio electrónicodigitalización del ocio convencional-piratería) pese a la escasez de medios líquidos, generando una contracultura a partir de la mismísima cultura hegemónica, que se expande incontrolable, a lomos de ésta.

\section{3.- Gramsci Ayer y Hoy: su recuerdo durante la era Eurocomunista hasta nuestros días}

En 1984, siete años después de la aparición del Eurocomunismo, y con la URSS todavía en el escenario Internacional, Antonio Garrigues Díaz-Cañabate reconoce la impronta de Gramsci en esta nueva corriente:

En la polémica de Lenin y Kautski (La moral proletaria y el renegado Kautsky) de principios de siglo se está tocando el fondo del mismo problema que hoy plantea el eurocomunismo. Es verdad que el eurocomunismo va ahora más lejos que el contenido de esas declaraciones y plantea inventos de hace más de 30 años pero el son, la música, es parecido Gramsci está en la misma línea, es la cabeza de ella, aunque su idea del partido príncipe tiene todavía una cierta vertiente totalitaria.

Pero más cerca de nosotros están los antecedentes de Togliatti y Longo, que derivan, como digo, de las posiciones teóricas de Antonio Gramsci32.

La corriente crítica con el nuevo movimiento no parecía interesada en reconocerle un origen tan prestigioso como el que sería un mártir del antifascismo. En 1979 Enver Hoxha publicaba su "Eurocomunismo es anticomunismo" 33 En el que se ataca como el título indica a esta nueva corriente: Ni una palabra para Gramsci. Solo para Carrillo, Togliatti, y en definitiva, todos los que estaban vivos y eran bombas políticas a desactivar en vez de figuras lejanas, mudas y manipulables.

En 1977 el estudioso marxista Fernando Claudín recordaba en una entrevista que "Para Marx, democracia y socialismo eran consustanciales". Ese mismo año, en un informe escrito para la Internacional Socialista, Gino Bianco habla de la posibilidad creciente de

\footnotetext{
vecinal al político, profesional, sindical o empresarial. Disponible en: www.20minutos.es/noticia/1996877/0/cis/barometro-noviembre-2013/sindicatos-partidos-politicos

31 Lafargue, P. (1998) El derecho a la pereza, Madrid, Manuel Pérez Ledesma

32 Garrigues Díaz-Cañabate, A. (1984). Berlinguer y el Eurocomunismo, en El País. Edición del 3 de Julio. Disponible en: http://elpais.com/diario/1984/07/03/internacional/457653622_850215.html.

33 Hoxha, E. (1979). Eurocomunismo es anticomunismo. Tirana: Instituto de estudios marxista leninista adjunto al CC del PTA, Casa editora "8 Nëntori". Disponible en: http://ciml.250x.com/archive/hoxha/spanish/spanish_eurocommunism_anticommunism.html.
} 
que varios gobiernos de Sud-Europa empiecen a contar con ministros comunistas dada su fuerza teórica. Y hace mención específica a la insistencia por parte del partido italiano, en la importancia de la hegemonía entendida según sus principios fundacionales:

Los franceses han reemplazado el concepto de dictadura del proletariado por una nueva noción, la de "hegemonía de la clase obrera". Los italianos proclaman también la importancia del concepto Gramsciano de hegemonía (y puede requerir un gran esfuerzo semántico - ha observado Walter Laqueur - separar las diferencias) y han afirmado su fidelidad al pluralismo. Sobre todo, los comunistas occidentales han puesto gran énfasis en su devoción a los valores democráticos ${ }^{34}$.

Sin salir del año, el filósofo José María Laso hace un temprano análisis sobre los orígenes del movimiento en el que una sección entera reconoce la aportación de la filosofía gramsciana a su concepción.

Para Gramsci ya no se trataba sólo de que en octubre se hubiese producido -según la formulación de Lenin- la ruptura del eslabón más débil de la cadena imperialista. En las condiciones de las sociedades industrializadas de Occidente la situación es muy distinta; la burguesía realizó en su momento la revolución y obtuvo, por uno u otro medio, el dominio del aparato estatal. Después, antes, o simultáneamente, según los casos, tuvo lugar un amplio proceso de sedimentación histórica en que ese dominio coercitivo se complementó con la dirección intelectual y moral de las masas subordinadas. Es decir, con la imposición de la hegemonía cultural, que aseguró el consenso popular en una medida jamás obtenida en las anteriores etapas de la historia de la explotación del hombre por el hombre ${ }^{35}$.

En 2002, sin embargo, el periodista César Vidal se pregunta por los orígenes de un movimiento que considera lejano (“¿Quién Creó el Eurocomunismo?” en Libertad Digital del 19 de Mayo) y en un mar de lenguaje marcadamente hostil, parece ignorar las raíces gramscianas, centrándose en Togliatti y sus puntos débiles:

Berlinguer había nacido en 1922 y, de manera que encontraba paralelos en otros dirigentes de partidos comunistas mediterráneos, pertenecía a una familia noble de Sassari, Cerdeña. Durante su juventud fue seguidor de Palmiro Togliatti, uno de los fundadores del PCI e importante funcionario de la Komintern. Togliatti había desempeñado entre otras misiones la de controlar a las Brigadas Internacionales en España y contaba no sólo con una enorme experiencia en tareas propagandísticas y represivas sino también con unas excelentes relaciones con Stalin. ${ }^{36}$

El Francés Marc Lazar (2011), en su artículo “El Eurocomunismo objeto de historia" reconoce el impacto de la Obra de Gramsci "en toda la Izquierda" pero la suya es solo una

34 Bianco, G. (1977). Social Democracia y Eurocomunismo, en Nueva Sociedad, no 35. Pág. 137-152.

35 Laso, J. M. (1977). Los precursores del Eurocomunismo, en Revista Argumentos, no 5. Pág. 21- 23.

36 Vidal, C. (2002). ¿Quién Creó el Eurocomunismo?, en Libertad Digital. Edición del 19 de Mayo. Disponible en: www.libertaddigital.com/otros/revista/articulos/23552286.htm. 
breve mención, sin alusión siquiera al concepto de hegemonía ${ }^{37}$.

\section{5.- CONCLUSIONES}

Consciente o inconscientemente, Gramsci estaba en las mentes de los fundadores del Eurocomunismo. Si bien, su aportación se ha ido diluyendo en la memoria colectiva con el paso del tiempo, como lo ha hecho el propio eurocomunismo, al que varios autores consideran un mero objeto de estudio histórico. Dada la actual situación de los partidos comunistas en Europa, bien podría entenderse este punto de vista, pues han estado perdiendo apoyo en favor de los socialdemócratas desde la caída de la Unión Soviética. Aquellos que participaron directamente en este nuevo experimento son recordados y generalizadamente elogiados (Caso de Santiago Carrillo en España, Georges Marchais en Francia, o de Enrico Berlinguer en Italia) por haber llevado al comunismo hasta la modernidad -o la traición para los más puristas-, aunque eso supusiera abandonar un terreno que consideraban conocido. Lo que pervive de Gramsci es la esencia de su concepto hegemónico -algo que habría sido del gusto de un filósofo de la praxis como élsegún la cual, la revolución es impensable dirigida por una minoritaria y confusa "Vanguardia del Proletariado" si no es como medio de instruir y atraer a la mayoría de la masa social (se considere esta obrera o de clase media) como medio último de victoria. Generalizar las ideas para alcanzar el poder, y no al revés. Una teoría para la que la Democracia es un sistema perfectamente valedero, aunque en la práctica ello traslade la lucha contra las fuerzas policiales y militares del estado burgués, a la lucha contra las no menos poderosas industrias editoriales $\mathrm{y}$ audiovisuales controladas por las clases privilegiadas.

Cuando Enver Hoxha afirmaba en su ataque anti-eurocomunista, que no es factible la reforma legal hacia el Socialismo, olvidaba los que tendrían que haber sido heroicos precedentes representados por Allende o por el más reciente Maurice Bishop (Isla de Granada) en cuyo caso los manejos moscovitas dieron la excusa a EE. UU. para intervenir, tras su ejecución por miembros de su propio partido. Evitaba, de paso, recordar que toda la idea de hegemonía fue hábilmente fundamentada por Gramsci en la figura del propio Lenin.

Puede considerarse pues, que el fundador del Partido Comunista Italiano ha sido olvidado por sus ideas, aunque su figura como Mártir antifascista siga muy presente para sus camaradas compatriotas. Sus ideas fueron sin duda simiente y justificación de este movimiento, pues los eurocomunistas buscaron los valores comunes a ambos lados del telón de acero, y buscaron usarlos para difundir entre sus respectivos pueblos el mensaje marxista, esquivando las dificultades para ello planteadas por las acciones internacionales del gobierno Soviético y su negativa repercusión en los medios occidentales. También comprendieron -algo que a día de hoy parece increíble que aún se sostuviera- que, si la revolución iba a llegar a Europa, no sería, desde luego, de forma violenta: lo dijo Gramsci, y 40 años después, resultó ser cierto.

37 Lazar, M. (2011). El Eurocomunismo objeto de Historia, en Historia del Presente, $\mathrm{n}^{\circ}$ 1. Pág. 59-66 http://hal.archives-ouvertes.fr/docs/00/97/27/31/PDF/lazar-el-eurocomunismo.pdf 


\section{6.- REFERENCIAS}

Adorno, T. \& Horkheimer, M. (1988). La industria cultural. Iluminismo como mistificación de masas Buenos Aires: Sudamericana.

Agencias (2013). El 37,3\% de los españoles dejó de pertenecer a un sindicato porque no defendía sus intereses, en Diario 20 minutos. Disponible en: www.20minutos.es/noticia/1996877/0/cis/barometro-noviembre-2013/sindicatospartidos-politicos. Consultado el 22 de abril de 2014.

Aurelio, M. (ed. 1995). Reflexiones. México: Ministerio de Educación y Cultura. Disponible en: $\quad$ www.edu.mec.gub.uy/biblioteca_digital/libros/M/Marco\%20Aurelio\%20\%20marco\%20aurelio\%20meditaciones.pdf. Consultado el 26 de abril de 2014.

Bianco, G. (1977). Social Democracia y Eurocomunismo, en Nueva Sociedad n n 35. Pág. 137152.

Carrillo, S. (1977). Eurocomunismo y Estado. Madrid: Crítica.

Corroto, T. y Polo, P. (2008). Navidades Rojas, en Diario Público. Disponible en: www.publico.es/culturas/183940/navidades-rojas. Consultado el 21 de abril de 2014.

Cyaheled, L. (1924). Matteotti è vivente. Nápoles: Vedova Ceccoli \& Figli.

Deutscher, I. (1967). Stalin: A Political Biography. Oxford: Oxford University Press.

Garrigues Díaz-Cañabate, A. (1984). Berlinguer y el Eurocomunismo, en El País. Edición del 3 de Julio. Disponible http://elpais.com/diario/1984/07/03/internacional/457653622_850215.html. Consultado el 26 de abril de 2014.

Gramsci, A. (1975). Cuadernos de la cárcel (vol. I). Turín: Einaudi. Pág. 464-465.

Hoxha, E. (1979). Eurocomunismo es anticomunismo. Tirana: Instituto de estudios marxista leninista adjunto al CC del PTA, Casa editora "8 Nëntori". Disponible en: http://ciml.250x.com/archive/hoxha/spanish/spanish_eurocommunism_anticommunis m.html. Consultado el 20 de abril de 2014.

Kruschev, N. (2010). Informe Secreto, en Cuadernos Socialistas. Pág. 36.

Lafargue, P. (1998). El derecho a la pereza. Madrid: Manuel Pérez Ledesma

Laso, J. M. (1977). Los precursores del Eurocomunismo, en Revista Argumentos $\mathrm{n}^{\circ} 5$. Madrid: Proprensa. Pág. 21- 23.

Lazar, M. (2011). El Eurocomunismo objeto de Historia, en Historia del Presente n ${ }^{\circ} 18$. Pág. 59-66. Disponible en: http://hal.archives-ouvertes.fr/docs/00/97/27/31/PDF/lazar-eleurocomunismo.pdf. Consultado el 16 de abril de 2014.

Marx, K. (1844). Escritos filosóficos y económicos. Berlín: Marx/Engels Gesamtausgabe.

Marx, K. (1989). Contribución a la crítica de la economía política. Moscú: Progreso.

Marx, K. y Engels, F. (2012). El manifiesto comunista. Barcelona: Nórdica libros.

Marx, K. (2001). Manuscritos económicos y filosóficos de 1844. Marxist Internet Archive, Kettering, Dayton. Disponible en http://pensaryhacer.files.wordpress.com/2008/06/manuscritos-filosoficos-yeconomicos-1844karl-marx.pdf. Consultado el 21 de abril de 2014.

Marx, Karl Heinrich (2010). El capital. Biblioteca Revolucionaria. Disponible en www.taringa.net/posts/info/10737381/Karl-Marx---El-Capital---Tomos-I-II-y-III.html.

Consultado el 26 de abril de 2014.

Marx, K. y Engels, F. (2005). Manifiesto del Partido Comunista . Málaga: Instituto de Estudios Sociales José Martí Pérez. Disponible 
www.educarteoax.com/pedagogizando/descargas/otros/Manifiesto_comunista.pdf.

Consultado el 26 de abril de 2014.

McLuhan, M. (2011). El medio es el masaje. Barcelona: Paidós.

Nietzsche, F. (1996). Genealogía de la moral. Madrid: Alianza.

Orwell, G. (1948). 1984. Londres: Signet.

Orwell, G. (1978). Mi guerra civil Española. Madrid: Destino.

Sandri, P. M. (2012). ¿En qué pensamos distinto los occidentales de los orientales?, en La Vanguardia Digital. Disponible en: $\underline{w w w . l a v a n g u a r d i a . c o m / e s t i l o s-d e-~}$ vida/20120302/54262328877/en-que-pensamos-distinto-los-occidentales-de-los-orientales.html.

Consultado el 26 de abril de 2014.

Piff, P. K. (2012). Higher social class predicts increasing unethical behaviour. Berkeley: Berkeley University Press.

Reagan, R. (1961). Ronald Reagan Speaks Out Against Socialized Medicine. Disco en LP. Disponible en: www.youtube.com/watch?v=AYrlDlrLDSQ. Consultado el 19 de abril de 2014.

Sans Mora, G. (2008). La vuelta a las Teorías de Marx, en Diario Público. Disponible en: www.publico.es/dinero/168187/la-vuelta-de-las-teorias-de-karl-marx. Consultado el 18 de abril de 2014.

Sans Mora, G. (2008). Viva Marx, Viva "El capital", en Diario Público. Disponible en www.publico.es/culturas/170354/viva-marx-viva-el-el-capital. Consultado el 26 de abril de 2014.

Vidal, C. (2002). ¿Quién Creó el Eurocomunismo?, en Libertad Digital. Edición del 19 de Mayo. Disponible en: www.libertaddigital.com/otros/revista/articulos/23552286.htm. Consultado el 26 de abril de 2014.

\section{Prof. Dr. David Caldevilla Domínguez.}

[CV] [Ohttp://orcid.org/0000-0002-9850-1350] [ 'GwVd-AnwAAAAJ] (U. Complutense de Madrid -España-) davidcaldevilla@ccinf.ucm.es

Licenciado y Doctor en CC.II., (Comunicación Audiovisual por la U. Complutense). Diplomado en Magisterio (U. de Zaragoza). Acreditado a titular (ANECA). Docente en: U. Complutense, U. Europea de Madrid, IED, ESERP e IPAM (Oporto -Portugal-). Ponente y conferenciante y profesor en varios títulos propios (Telemadrid, Walter \& Thompson, McCann...). Secretario General de la SEECI (Sociedad Española de Estudios de Comunicación Iberoamericana) y del "Fórum Internacional de la Comunicación y Relaciones Públicas" (Fórum XXI). Investigador Principal (IP) del Grupo Complutense de Investigación 'Concilium, grupo de comunicación'. Autor de más de 50 artículos científicos, de más de 70 ponencias en Congresos y de 6 libros. Miembro de comités científicos en congresos y revistas científicas internacionales. Director de los Congresos CUICIID. Tertuliano radiofónico.

\section{Enrique García García:}

[CV] [Ohttp://orcid.org/0000-0002-1872-5013] [ 'Gf-7A04wAAAAJ] (USP CEU) sleater@hotmail.com

Licenciado en Periodismo, humanidades y CC. de la Información por la Universidad San 
Pablo CEU. Máster CES en Periodismo Audiovisual. Director del Magazine "Cultura Pop" en CVB radio, ha cubierto todo tipo de información en su paso por la prensa y la radio: desde economía en el diario "el economista" a deportes para COPE y sociedad para Radio Intercontinental. 